\title{
THE LIGHT MICROSCOPY AND ULTRASTRUCTURAL CHARACTERISTICS OF SARCOCYSTIS FUSIFORMIS INFECTING BUFFALOES IN IRAQ
}

By

NAKSHEEN M. ARDALAN

Department of Biology, College of Science for Woman, University of Baghdad, Al-Jadirya St, Baghdad, Iraq (Correspondence: naksheen_ardalan@yahoo.com)

\section{Abstract}

Samples from fresh muscles of 2-12 years old buffalo (Bubalus bubalis) from Al-Shuala, Baghdad were examined for Sarcocystis infection. Macroscopic ovoid Sarcocystis embedded in the muscle tissues of the examined buffalo were detected, they measured 150$223(209 \pm 7) \mu \mathrm{m}$ length and 35-130 (85+3) $\mu \mathrm{m}$ width. Esophagus was the highly infected organ followed by diaphragm, tongue while the heart muscles were the lowest infected part. The cyst cavity was compartmentalized by septa derived from the ground substance located under the primary cyst wall. By TEM, the primary cyst wall bordered sarcocysts, 0.08-0.22 $\mu \mathrm{m}$ in thickness, raised from the parasitophorous vacuolar membrane and surrounded by a secondary cyst wall of host origin. The primary cyst wall had irregular wall folds with numerous cauliflower projections of variable size and shape accompanied with a knob-like electron dense elevation. The interior of the cyst contained merozoites consisted of the structural elements of the Apicomplexa, polar rings, micronemes, conoid and rhoptries. Keywords: Bubalus bubalis, Sarcocystis fusiformis, light and electron microscopy

\section{Introduction}

Sarcocystosis is a zoonotic and protozoan disease often prevalent in household animals like buffaloes, cattle, and pigs. Sarcocystis is an intracellular, cyst-forming coccidian parasite under the phylum Apicomplexa and family Sarcocystidae with two obligate hosts, including a definitive carnivorous host and an intermediate omnivorous or herbivorous host (Fayer et al, 2015). Casualties of the pathogen in domestic cattle may lead to severe fatalities such as abortion, reduced milk yield, neurologic signs, and weight loss. The infection with macroscopic Sarcocystis leads to meat's low market profile along with condemnation of the infected hosts (Calero-Bernal et al, 2016). The main source of Sarcocystis infection in humans is meat and meatderivatives by ingestion of well-developed tissue cysts containing bradyzoites (Abu-Elwafa et al, 2015). Bubalus bubalis (water buffalo) acts as the natural reservoir harbored four species of Sarcocystis: S. fusiform is, S. buffalonis, S. levinei \& S. sinensis (Gjerde, 2016; Gjerde et al, 2017). Many studies were done on Sarcocystis species infecting slaughtered animals in Iraq. Latif et al. (1999) recorded Sarcocystis spp. in edible animals, and added that the prevalence percentage of macroscopic cysts were 4.1, 33.6, 0.2, $15.6 \& 0$, but the microscopic one were 97.0, 97.4, 97.8, $82.9 \& 91.6$ for sheep, goat, cattle, buffaloes \& camels respective1y. El-Dakhy et al. (2011) reported S. fusiformis \& S. levinei in buffaloes. Whaeeb et al. (2016) in Baghdad studied the molecular structure of four Sarcocystis species from sheep esophagus and muscle. Zangana and Hussein (2017) in Duhok Province, Kurdistan region, Northern Iraq studied the prevalence of $S$. ovicanis and $S$. capricanis in sheep and goats tongue muscle. Scioscia et al. (2017) reported three S. fusiformis.

The present study aimed to describe Sarcocystis fusiformis isolated from the water buffaloes by the light and transmission electron microscopy.

\section{Material and Methods}

Macrocysts of Sarcocystis spp. were isolated from heavily infected esophagus of an adult male buffaloe Bubalus bubalis Linnaeus, 1758 (Mammalia: Bovidae) freshly slaughtered at Al-Shuala Abattoir, Baghdad over the year 2018. Tissue samples from the slaughterhouse were sent to the Parasitology Lab, Department of Biology, College of Science for Woman, preserved in ice-bags (Huong, 1997), and stored in refrigeration 
tell needed. Macroscopically Sarcocystis was (3-4x1-2 mm) excised from esophagus, preserved in the desired fixative for light microscopy, and TEM examinations.

Histopathological studies: Buffered formal solution of $10 \%(\mathrm{pH} \mathrm{7.3)}$ was used to immobilize small pieces of $3 \mathrm{~mm}$ infected muscle samples for at least $12 \mathrm{hrs}$. Phosphate buffer was used for washing for 2-3 times of 10 min. each, samples were dehydrated in ethanol 50\%, 70\%, 80\%, 90\%, 96\% \& 100\%, cleared in xylol and embedded in paraffin at $62^{\circ} \mathrm{C}$. Sections of $5 \mu \mathrm{m}$ thickness were cut by the rotary microtome (Ardalan et al, 2017). After wax removing, sections were hydrated in a descending series of ethanol and stained with hematoxylin and eosin (H\&E). Sections were microscopically examined and photographed by attached digital camera (Canon).

TEM examination: Very small muscle pieces of the highly infected animals were immediately preserved in 3\% glutaraldehyde fixative for at least $4 \mathrm{hrs}$ at $4^{\circ} \mathrm{C}$. The muscles were rinsed overnight in $0.2 \mathrm{M}$ sodium cacodylate buffer at $4{ }^{\circ} \mathrm{C}$ post-fixation and osmification performed in $1 \%$ cold osmium tetroxide in $0.2 \mathrm{M}$ sodium cacodylate at $\mathrm{pH} 7.2$ for $2 \mathrm{hrs}$. Buffer was done after dehydration in ethanol grades of $50 \%, 70 \%, 80 \%, 90 \%$, $96 \% \& 99.9 \%$ and clarified in propylene oxide for 20 minutes. The samples were put in equal volumes of propylene oxide and resin (Epon-Araldite mixture), rotated for at least one day and put into flat or BEEM capsule molds (positioned near molds tips). The resin was put overnight in an oven at $60^{\circ} \mathrm{C}$ (Mollenhauer, 1964). The semi-thin sections were stained with toluidine blue. Ultrathin sections were examined with a Philips (208S) TEM at 80-100 KV.

\section{Results}

The Sarcocystis infected buffalo; macroscopic cysts were embedded in the animals' muscle tissues (Figs. 1a). Cysts were ovoid with dimensions of 150-223 (209+7) $\mu \mathrm{m}$ length $x$ 35-130 (85 \pm 3$) \mu \mathrm{m}$ width (Figs. 1b). Esophagus was the highly infected organ fo- llowed by diaphragm, tongue and muscles, but the heart muscles were least infected.

Light microscopy: Histological sections (Figs. 1c) of infected muscle showed that cyst cavity was divided into many chamberlike compartments separated from each other by septa derived from the ground substance located under the primary cyst wall. In semithin sections via sarcocysts (Figs. 1d), cyst compartments were surrounded by primary cyst wall underneath was a ground substance. Two parasitic stages were within the cyst, metrocytes that acquired a faint stain located directly under the ground substance and the merozoites, which filled most of the cysts interior area was darkly stained with toluidine blue.

In the present study, TEM examination of ultrathin sections showed that all cysts surrounded by a clear cyst wall of $0.08-0.22 \mu \mathrm{m}$ in thickness developed from parasitophorous vacuolar membrane (Figs. 2a-c). A well developed secondary cyst wall also presided. A crucial factor for species identification such as the structure of the primary cyst wall, had revealed that this wall had irregular folds with numerous cauliflower projections or protrusions of variable size and shape. Also, knob-like electron dense elevations were accompanied by projections. Within projections there were many fibrillar elements. $\mathrm{Nu}$ merous vesicles, vacuoles and mitochondria of host cell were surrounding these projections. In L.S, protrusions measured 0.49-0.83 $(0.67 \pm 0.02) \mu \mathrm{m}$, beneath primary cyst wall, a relatively thick homogenous ground substance measured $0.074-0.53 \mu \mathrm{m}( \pm 0.29)$ thickness. Merozoites (Figs. 2d) of the sarcocysts showed the same ultrastructural merozoite patterns of all Apicomplexa members. They were banana shaped with blunt posterior and pointed anterior end, and measured 15.2$16.4(14.9 \pm 4 \mu \mathrm{m}) \times 2.8-6.1 \mu \mathrm{m}(5.5 \pm 2 \mu \mathrm{m})$. Plasmalemma enclosed the whole cell, but was interrupted at the anterior and posterior polar rings and at micropore. The micropore (feeding organelle) was formed by the invagination of outer membrane of pellicle supp- 
orted by two thickened structures raised by the interruption of the inner membranous layer. Merozoite apical complex (Fig. 2e) consisted of conoid at the anterior polar ring. It's a hollow cone-like or hump-structure. Rhoptries were paired club-shaped and dense structures with a gland like-appearance. Unlike their name implication, micronemes appeared as rice grains and were numerous filling anterior regions but, appeared round in cross sections and may be secretory in function.

\section{Discussion}

A wide range of mammals and avian harbor Sarcocystis was uncommon in ectothermic vertebrates (Dubey et al, 2017). The coccidian nature of Sarcocystis was elucidated (Fayer, 1972; Rommel et al, 1972). The infection profile in the present study indicated that these domestic animals are at a high risk of infection due to their surreal inter-relationship with other domestic animals (Collier et al, 1998). Prevalence of infection in domestic animals in different countries were $68 \%$ in pigs (Lukesová et al, 1986), 100\% in sheep (Ford, 1987), 90\% in cattle and horses 93 (Fukuyo et al, 2002), 93\% in donkeys (El-Ganayni, 2003), 64\% camels (Al-Quraishi et al, 2005), 84\% in Egyptian caws and $28 \%$ in buffaloes Khalifa et al. (2008) to $25.5 \%$ (Metwally et al, 2014), 77\% \& $79.4 \%$ goats (Morsy et al, 2011), 73.1\% in Argentina lions (Moré et al, 2011), 25\% in Egyptian horses (Sakran et al, 2013) 34.7\% in swine (Grikieniene, 1994), in cats the incidence varied between $17.6 \%$ (Lukes ova et al, 1986), to $10 \%$ (Gillis et al, 2003) and $0.03 \%$ in dogs (Barutzki and Schaper 2011), in birds the incidence varied between $36.5 \%$ (Černá 1984) to 62\% (Olias et al, 2011), to $8 \%$ in Egyptian swamp chicken (El-Morsey et al, 2013), 25\% in Jackdaw birds (Prakas et al, 2013).

Generally, Sarcocystis varied in morphology as to species and age (JyothiSree et al, 2017). Commonest ones were filamentous, elongated, or globular (Dubey et al, 1989).

The Sarcocystis was reported with different forms according to species; either stumpy as in S. zamani (Mehlhorn et al, 1976), spindleshaped as in S. idahoensis (Bledsoed, 1980), streak-like as in $S$. crotali (Entzeroth et al, 1985), slender as in S. clethrionomyelaphis (Matuschka, 1986), spherical as in S. hoarensis (Matus-chka and Bannert, 1989), ovoid as in S. moulei (Abdel-Ghaffar et al, 1989), filiform as in $S$. dubeyella (Stolte et al, 1998), elliptical as in S. felis in cats (Elsheikha et al, 2006) or thick thread as in $S$. corvusi in jackdaw (Prakas et al, 2013). The morphological characters of primary cyst wall played a pivotal role in the genus Sarcocystis identification (Mehlhorn and Heydorn, 1978: Dubey et al, 2006). According to primary cyst wall, mature Sarcocystis was basically differentiated into thick-walled if the wall outer portions have prominent long projections or thin walled if the protrusions were short or disappear (Dar et al, 2017). Hence, the comparative parameter of species difference was restricted to the mature cysts (Abdel-Ghaffar et al, 1990; 2009; Modrý et al, 2000; Mehlhorn, 2008; Latif et al, 2015) as young cysts was somewhat similar.

In the present study, a unipolar membrane limit coccidian parasitophorous vacuole led to rise of recovered macroscopic Sarcocystis (Scholtyseck et al, 1974; Mehlhorn and Heydorn, 1978; Abdel-Ghaffar et al, 1989, AlQuraishi et al, 2005). The cyst wall formation from the parasitophorous vacuole wall during cyst development was a typical feature of all Sarcocystis species. The origin of cyst wall was controversies. Some authors reported that it was of a host origin, others suggested that it was of a parasitic origin, but the third opinion claimed that the wall originated from both sources (Mehlhorn and Heydorn, 1978). Post-initial parasitophorous vacuole wall was formed and cyst formation began, the underlying layer of osmiophilic material strengthened to become the primary cyst wall (Mehlhorn, 2008; Dubey et al, 2016). The primary cyst wall structure widely varied among different developmental stages, and thus the cyst fine structure wall was 
used with care, as species an identification criterion (Scholtyseck et al, 1974; Modrý et al, 2000; Dubey et al, 2006).

In some Sarcocystis species, the wall was thick and folded many times forming irregular wall folds with numerous cauliflower projections of variable size and shape, with knob-like electron dense elevations accompanied by projections. This agreed with Abdel-Ghaffar et al. (1989) in buffaloes. The primary wall and its complex structures a layer of fibril material of the host origin enclosing the parasitized host cell lappeared as a secondary cyst wall, with a significant response from the host to parasite (Mehlhorn and Scholtyseck, 1973, Abdel-Ghaffar et al, 1989; Ahmadi et al, 2015). Under the primary cyst wall a relatively thin homogenous layer or ground substance extended outward via protrusions middle portion leaving a clear zone on both side inwarded via the cyst as septa, one of the characteristic features of genus Sarcocystis (Hu et al, 2017). The septa divided the cyst cavity into many chamber-like structures with two parasitic forms: the meterocytes \& merozoites. The globular metrocytes occupied the cyst peripheral portion (chambers) just below the ground substance, with banana shaped merozoites concentrated in central region. This agreed with Matuschka and Bannert (1989) and Dubey et al. (2017). The present study coincided with $S$. fusiformis recorded in Iraqi buffaloes by Dakhil et al. (2017) focused on parasite macroscopic genetic identification.

\section{Conclusion}

The present study is the first documented light and ultrastructural study that confirmed the taxonomy of Sarcocysts isolated from the buffaloes in Baghdad as Sarcocystis fusiformis

\section{References}

Abdel-Ghaffar, F, Bashtar, AR, Ashour, MB, Sakran, TH, 1990: Life cycle of Sarcocystis gongyli Trinci 1911 in the skink Chalcides ocellatus and the snake Spalerosophis diadema. Parasitol. Res. 76:444-50.

Abdel-Ghaffar, F, Heydorn, AO, Mehlhorn, H, 1989: The fine structure of cysts of Sarcocystis moulei from goats. Parasitol. Res. 75:416-8
Abdel-Ghaffar, F, Mehlhorn, H, Bashtar, AR, Al-Rasheid, K, Sakran, TH, Al-Fayoumi, H, 2009: Life cycle of Sarcocystis camelicanis infecting the camel (Camelus dromedarius) and the dog (Canis familiaris), light and electron microscopic study. Parasitol. Res. 106:189-95.

Abu-Elwafa, S, Al-Araby, M, Abbas, I, 2015: Sarcocystis fusiformis infecting water buffaloes (Bubalus bubalis) in Dakahlia Governorate, Egypt. Int. J. Adv. Res. 3, 2:116-20

Ahmadi, MM, Hajimohammadi, B, Eslami, G, Oryan, A, Yasini, SA, et al, 2015: First identification of Sarcocystis hominis in Iranian traditional hamburger. J. Parasit. Dis. 39, 4:770-2. Al-Quraishi, SA, Bashtar, AR, Al-Rasheid, K A, Abdel-Ghaffar, F, 2005: The prevalence and ultrastructure of Sarcocystis species infecting camels (Camelus dromedaries) Slaughtered in Riyadh City, Saudi Arabia. Saudi J. Biol. Sci. 11, 2:135-42.

Barutzki, D, Schaper, R, 2011: Results of parasitological examinations of fecal samples from cats and dogs in Germany between 2003 \& 2010. Parasitol. Res. 109, 1:545-60.

Bledsoed, B, 1980: Sarcocystis Idahoensis sp. n. in deer mice Peromyscus maniculatus (Wagner) and geopher snakes Pituophis melanoleucus (Daudin) J. Protozool. 27, 1:93-102

Calero-Bernal, R, Cerqueira-Cézar, CK, Verma, SK, Mowery, J, Carmena, D, et al, 2016: Sarcocystis arctica (Apicomplexa: Sarcocystidae): ultrastructural description and its new host record, Alaskan wolf (Canis lupus). Parasitol. Res, 115, 7:2893-7.

Černá, ̌̌, 1984: The role of birds as definitive hosts and intermediate hosts of heteroxenous coccidians. J. Protozool. 31, 4:579-81

Collier, L, Balows, A, Sussman, M, 1998: Sarcocystis Isospora and Cyclospora. In: Gransden WR (Ed), Topley and Welson's: Microbiology and Microbial Infections. $9^{\text {th }}$ ed. vol.5. New York, Oxford University Press Inc.

Dakhil, HG, Abdallah, BH, Abdallah, FA, 2017: Molecular identification of Sarcocystis fusiformis and $S$. moulei infecting water buffaloes (Bubalus bubalis) in southern Iraq. Wld. J. Pharma. Res. 6, 3:215-29.

Dar, KH, Bhat, MM, Shafi, M, 2017: Prevalence and organ-wise distribution of sarcocystiosis in buffaloes of Mohali, Punjab. J. Parasit. Dis. 41, 2:318-21.

Dubey, JP, Moré, G, van Wilpe, E, CaleroBernal, R, Verma, SK, et al, 2016: Sarcocystis 
rommeli, n. sp. (Apicomplexa: Sarcocystidae) from cattle (Bostaurus) and its differentiation from Sarcocystis hominis. J. Euk. Microbiol. 63, $1: 62-8$.

Dubey, JP, Naji, N, Mowery, J, Verma, S, Calero-Bernal, R, 2017: Identification of macroscopic sarcocysts of sarcocystis cameli from onehumped camel (camelus dromedarius) in Iraq. J. Parasitol. 103, 2:168-9.

Dubey, JP, Rosenthal, BM, Morales, JA, Alfaro, A, 2006: Morphologic and genetic characterization of Sarcocystis sp. from the African grey parrot, Psittacus erithacus, from Costa Rica. Acta Parasitol. 51:161-8

Dubey, JP, Speer, CA, Fayer, R, 1989: Sarcocystosis of Animals and Man. $1^{\text {st }}$ ed., CRC Press, Boca Raton

El-Dakhly，KM, El-Nesr，KA, El-Nahass，S, Hirata, A, Sakai, H, et al, 2011: Prevalence and distribution patterns of Sarcocystis spp. in buffaloes in Beni-Suef, Egypt. Trop. Anim. Hlth. Prod. 43:1549-54.

El-Ganayni, SE, 2003: Ultrastructure of Sarcocystis fayeri infecting donkeys (Equus asinus) in El-Menia Governorate, Egypt. J. Egypt. German Soc. Zool. 42, D:33-46

El-Morsey, A, El-Seify, M, Desouky, AR, Abdel-Aziz, MM, Sakai, H, et al, 2013: Morphologic identification of a new Sarcocystis sp. in the common moorhen (Gallinula chloropus) (Aves: Gruiformes: Rallidae) from Brolos Lake, Egypt. Parasitol Res 113(1): 391-397.

Elsheikha, HM, Kennedy, FA, Murphy, AJ, Soliman, M, Mansfieled, LS, 2006: Sarcocystosis of Sarcocystis felis in cats. J. Egypt. Soc. Parasitol. 36, 3:1071-9

Entzeroth, R, Chobotar, B, Scholtyseck, E, Nemesri, L, 1985: Light and electron microscope study of Sarcocystis sp. from the fallow deer (Cervivs lama). Parasitol. Res. 71:33-9

Fayer, R, 1972: Gametogeny of Sarcocystis in cell culture. Science 175: 65-67

Fayer, R, Esposito, DH, Dubeya, JP, 2015: Human infections with Sarcocystis species. Clin. Microbiol. Rev. 28, 2:295-311.

Fukuyo, M, Battsetseg, G, Byambaa, B, 2002: Prevalence of Sarcocystis infection in horses in Mangolia. Southeast-Asian J. Trop. Med. Pub. Hlth. 33, 4:718-9.

Gillis, KD, Mackay, RJ, Yowell, CA, Levy, J K, Greiner, EC, et al, 2003: Naturally occuring sarcocystis infection in domestic cats (Felis catus). Int. J. Parasitol. 33:877-83.
Gjerde, B, 2016: Molecular characterization of Sarcocystis bovifelis, Sarcocystis bovini n. sp., Sarcocystis hirsuta and Sarcocystis cruzi from cattle (Bos taurus) and Sarcocystis sinensis from water buffaloes (Bubalus bubalis). Parasitol. Res. 115, 4:1473-92.

Gjerde, B, Giacomelli, S, Bianchi, A, Bertoletti, I, Mondani, H, et al, 2017: Morphological and molecular characterization of four Sarcocystis spp., including Sarcocystis linearis n. sp., from roe deer (Capreolus capreolus) in Italy. Parasitol. Res. 116, 4:1317-38.

Grikienienè, J, 1994: Sarcocystis in cattle and swine: Significance for man and mans' role in its spreading. Proceed. Sci. Conf. Anim. Husbandry and Ecology, Kaunas, Lithuania.

Hu, JJ, Wen, T, Chen, X, Liu, T, Esch, G W, et al, 2016: Prevalence, morphology, and molecular characterization of Sarcocystis heydor$n i$ sarcocysts from cattle (Bos taurus) in China. J. Parasitol. 102, 5:545-8.

Huong, LTT, Dubey, JP, Nikkilä, T, Uggla, A, 1997: Sarcocystis buffalonis n. sp. (Protozoa: Sarcocystidae) from the water buffalo (Bubalus bubalis) in Vietnam. J. Parasitol. 83:471-4 JyothiSree, C, Venu, R, Samatha, V, Malakondaiah, P, Rayulu, VC, 2017: Prevalence and microscopic studies of Sarcocystis infection in naturally infected water buffaloes (Bubalus bubalis) of Andhra Pradesh. J. Parasitol. Dis. 41, 2: 476-82.

Latif, BM, Al-Delemi, JK, Mohammed, BS, Al-Bayati, SM, Al-Amiry, AM, 1999: Prevalence of Sarcocystis spp. in meat-producing animals in Iraq. Vet. Parasitol. 84, 1/2:85-90.

Latif, BM, Kannan-Kutty M, Muslim, A, Husain, J, Omar, E, et al, 2015: Light microscopy and molecular identification of Sarcocystis spp. in meat producing animals in Selangor, Malaysia. Trop. Biomed. 32, 3:444-52.

Lukesová, D, Nevole, M, Haidová, B, 1986: The extent of the incidence of sarcocystosis in cattle and pig farms. Vet. Med. 31, 9:521-30

Matuschka, FR, 1986: Sarcocystis clethrionomyelaphis $\mathrm{n}$. sp. from snakes of the genus Elaphe and different voles of family Arvicolidae. J. Parasitol. 72:226-31

Matuschka, FR, Bannert, B, 1989: Recognition of cyclic transmission of Sarcocystis stehlinii n. sp. in the Gran Canadian giant lizard. J. Parasitol. 75:383-7

Mehlhorn, H, 2008: Encyclopedic Reference of Parasitology, $3^{\text {rd }}$ Ed. Springer, Verlag, Berlin 
Mehlhorn, H, Scholtyseck, E, 1973: Elektron en mikrokopischeUntersuchungen an Cystenstadien von Sarcocysti stenella aus der Oesophagus Muskulatur des Schafes. Parasitol. Res. 41, 4: 291-310.

Mehlhorn, H, Hartley, WJ, Heydorn, AO, 1976: A comparative ultrastructural study of the cyst wall of 13 Sarcocystis species. Protistologica 12:451-67.

Mehlhorn, H, Heydorn, AO, 1978: Sarcosporidia (Protozoa, Sporozoa): Life cycle and fine structure. Adv. Parasitol. 16:73-92

Mollenhauer, HH, 1964: Plastic embedding mixtures for use in electron microscopy. Stain Technol. 39:111-4

Metwally, AM, Abd-Ellah, MR, Al-Hosary, A A, Omar, MA, 2014: Microscopic and serologic studies on Sarcocystis infection with first report of S. cruzi in buffaloes (Bubalus bubalis) in Assiut, Egypt. J. Parasitol. Dis. 38, 4:378-82.

Moré, G, Abrahamovich, P, Jurado, S, Bacigalupe, D, Marin, JC, et al, 2011: Prevalence of Sarcocystis spp. in Argentinean cattle. Vet. Parasitol. 177, 1/2:162-5.

Modrý, D, Koudela, B, Slapeta, JR, 2000: Sarcocystis stenodactylicolubris n. sp., a new sarcosporidian coccidium with a snake-gecko heteroxenous life cycle. Parasite 7, 3:201-7.

Morsy, K, Saleh, A, Al-Ghamdi, A, AbdelGhaffar, F, Al-Rasheid, K, et al, 2011: Prevalence pattern and biology of Sarcocystis capracanis infection in the Egyptian goats: a light and ultrastructural study. Vet. Parasitol. 181:75-82.

Olias, PP, Olias, L, Krücken, J, Lierz, M, Gruber, AD, 2011: High prevalence of Sarcocystis calchasi sporocysts in European Accipiter haw$k s$. Vet. Parasitol. 175, 3/4:230-6.

Prakas, P, Kutkienè, L, Butkauskas, D, Sruo- ga, A, Zalakevičius, M, 2013: Molecular and morphological investigations of Sarcocystis corvusi sp. nov. from the jackdaw (Corvus monedula). Parasitol. Res. 112, 3:1163-7.

Rommel, M, Heydorn, AO, Gruber, V, 1972: BeitragezumLebenszyklus der Sarkosporidien. I. Die Sporozyste von S.tenella in den Fazes der Katze. Berliner \& Münchener tierärztliche Wochenschrift 85:101-5.

Sakran, T, Al-Hroub, A, Ahmed, A, 2013: Studies on Sarcocystis infecting domestic horse. Am. J. Res. Commun. 1, 6:39-53

Scholtyseck, E, Mehlhorn, H, Miiller, BEG. 1974: Feinstruktur der Cyste und Cystenw and von Sarcocystis tenella, Besnoitia jellisoni, Frenkelia sp. und Toxoplasma gondii. J. Protozool. 21:284-94

Scioscia, NP, Olmos, L, Gorosábel, A, Bernad, L, Pedrana, J, et al, 2017: Pampas fox ( $L y$ clopex gymnocercus) new intermediate host of Sarcocystis svanai (Apicomplexa: Sarcocystidae). Parasitol. Int. 66(3): 214-8.

Stolte, M, Odening, K, Quand, TS, Bengis, R G, Bockhardt, I, 1998: Sarcocystis dubeyella $\mathrm{n}$. sp. and Sarcocystis phacochoeri n. sp. (Protozoa: Sarcocystidae) from the warthog (Phacochoerus aethiopicus) in South Africa. J. Euk. Microbiol. 45, 1:101-4.

Whaeeb, ST, Faraj, AA, Khalaf, IA, 2017: Molecular study of four species of Sarcocystis isolated from sheep esophagus and inter skeleton muscle in Baghdad. Wld. J. Pharma. Res. 5, 8: 158-65.

Zangana, IK, Hussein SN, 2017: Prevalence of Sarcocystis species (Sarcocystis ovicanis and Sarcocystis capricanis) in tongue muscle of sheep and goats in Duhok Province, Kurdistan Region, North Iraq. Sci. J. Koya Univ. 5, 3:36-40

\section{Explanation of figures}

Fig. 1 (a, b): Sarcocystis fusiformis (arrows) embedded in a buffalo esophagus (a) and isolated (b). Macroscopic spindle shaped and whitish sarcocystis embedded in host muscles.

Fig. 1 (c, d): Photomicrograph showing: (c) a histological section through host muscles of esophagus infected with a parasite sarcocyst within parasitophorous vacuoles (PV) and stained with H\&E. Cyst bordered with wall $(\mathrm{CW})$ underlined by a layer of ground substance extended into the interior of the cyst as septa dividing it into compartments enclosing merozoites (ME), $x$ 140. (d) Semi-thin section through a sarcocyst (Sc) stained with toluidine blue showing cyst compartments separated from each other by septa (SE), 240

Fig. 2 (a-c): TEM of ultrathin section through sarcocysts showed ultrastructural characteristics of primary cyst wall underlined by a layer of thick ground substance (GS) extended into cyst as septa dividing it into compartments. Primary cyst wall with cauliflower-like protrusions (PT) of variable size, and shape with knob (KB) like structures surrounding each protrusion outer layer with internal microtubules (MT). HC abbreviated for host cell. x 13,000; x 22,000

Fig. 2 (d, e): TEM showed (d) different cross sections through merozoites (ME). Apical complex structural characteristics for motile infective stages as micronemes (MN), rhoptries $(\mathrm{RH})$, and conoid (C). MP for a micropore. X 17,000. (e) TEM showed ultrastructural characteristics of the apical complex of merozoites. Anterior polar ring (APR) is the terminal part of merozoite, mechanical penetrating organ represented by two conoids (C), secretory organelles represented by micronemes (MN) and rhoptries (RH). X 25,000 


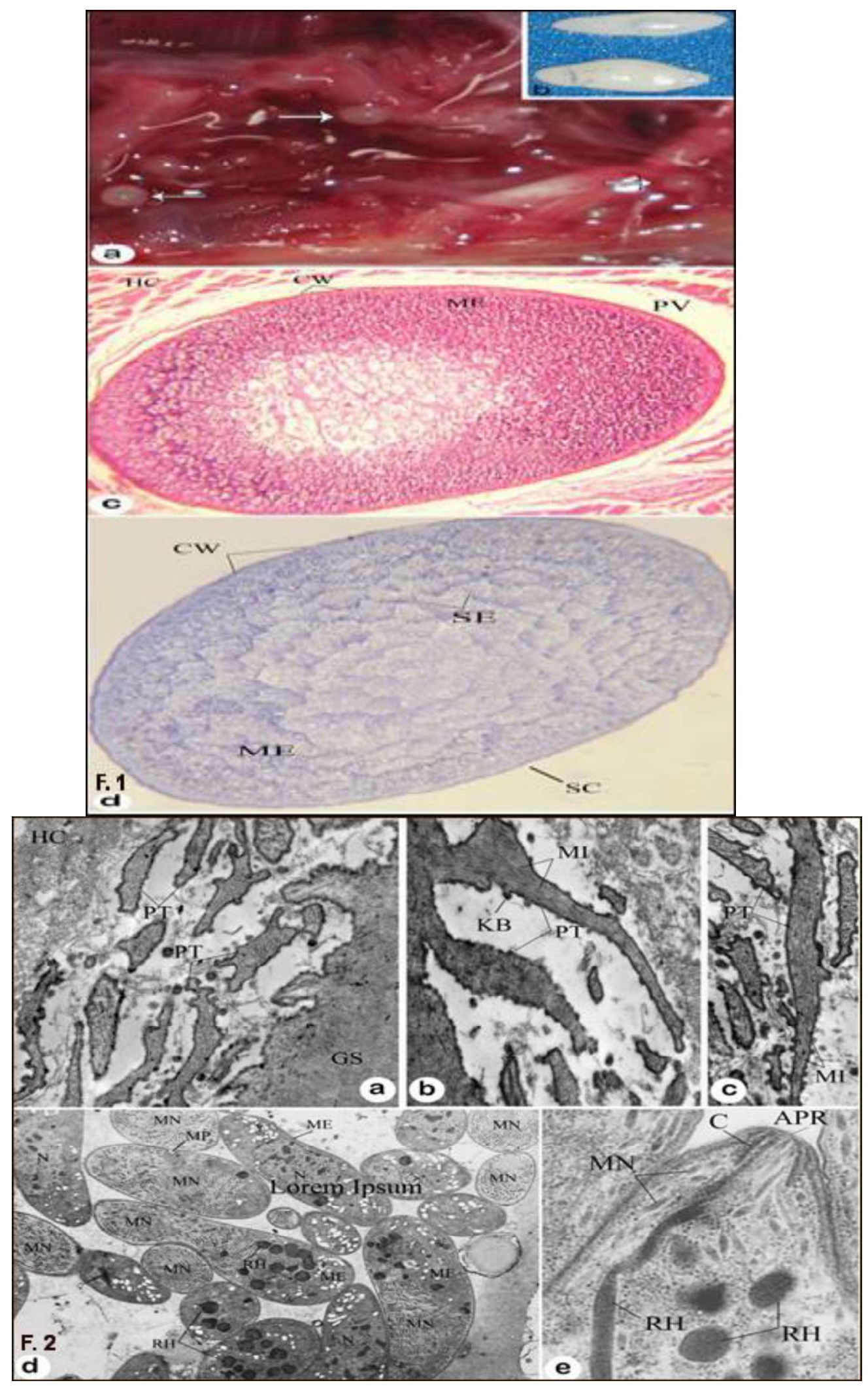

